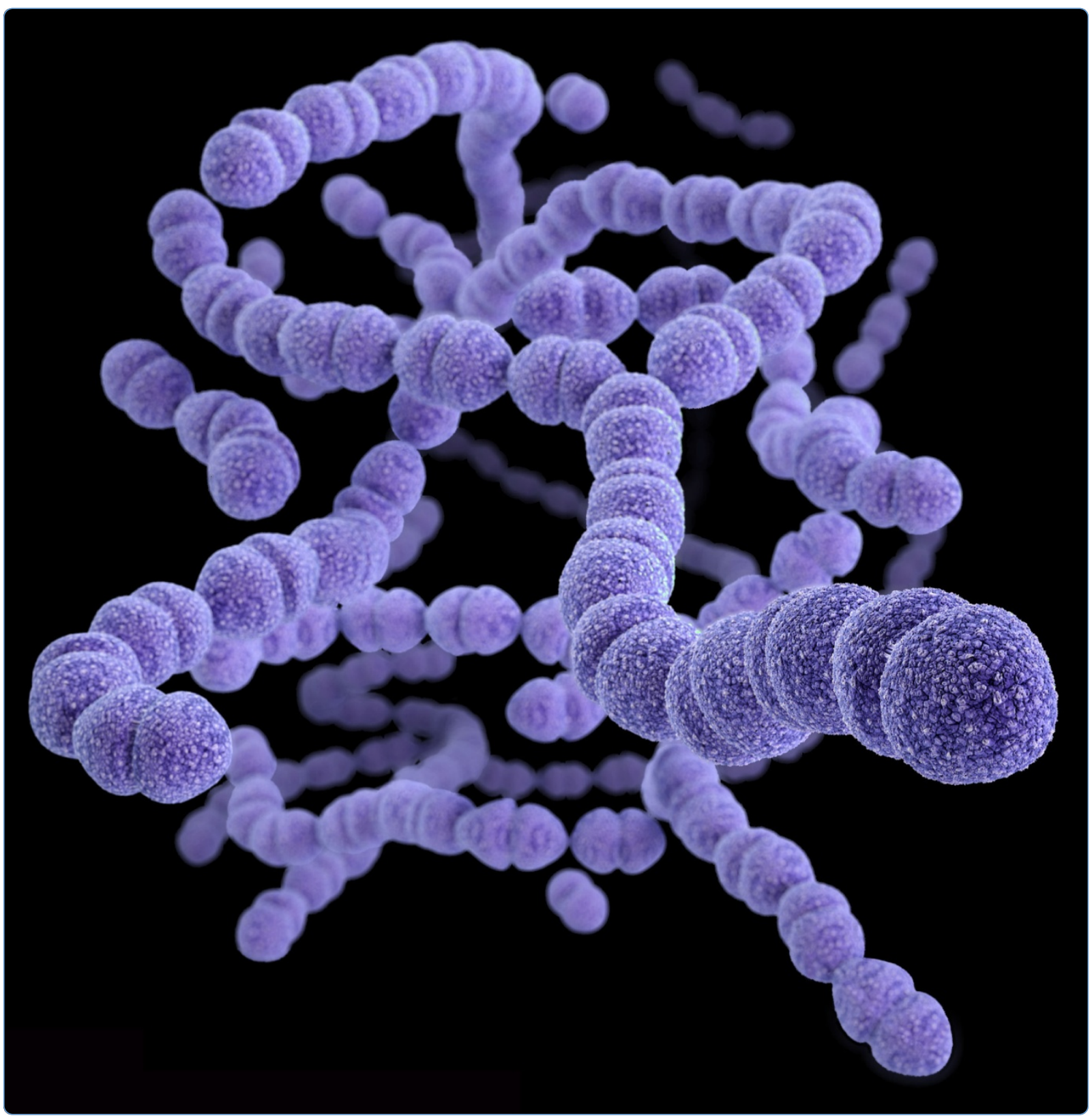

Attributable healthcare utilization and cost of pneumoniae due to drug-resistant Streptococcus pneumoniae: a cost analysis

Reynolds et al. 


\title{
Attributable healthcare utilization and cost of pneumoniae due to drug-resistant Streptococcus pneumoniae: a cost analysis
}

\author{
Courtney A Reynolds ${ }^{1 *}$, Jonathan A Finkelstein ${ }^{2,3}$, G Thomas Ray ${ }^{4}$, Matthew R Moore ${ }^{5}$ and Susan S Huang ${ }^{1}$
}

\begin{abstract}
Background: The burden of disease due to S. pneumoniae (pneumococcus), particularly pneumonia, remains high despite the widespread use of vaccines. Drug resistant strains complicate clinical treatment and may increase costs. We estimated the annual burden and incremental costs attributable to antibiotic resistance in pneumococcal pneumonia.

Methods: We derived estimates of healthcare utilization and cost (in 2012 dollars) attributable to penicillin, erythromycin and fluoroquinolone resistance by taking the estimate of disease burden from a previously described decision tree model of pneumococcal pneumonia in the U.S. We analyzed model outputs assuming only the existence of susceptible strains and calculating the resulting differences in cost and utilization. We modeled the cost of resistance from delayed resolution of illness and the resulting additional health services.

Results: Our model estimated that non-susceptibility to penicillin, erythromycin and fluoroquinolones directly caused 32,398 additional outpatient visits and 19,336 hospitalizations for pneumococcal pneumonia. The incremental cost of antibiotic resistance was estimated to account for 4\% (\$91 million) of direct medical costs and 5\% (\$233 million) of total costs including work and productivity loss. Most of the incremental medical cost ( $\$ 82$ million) was related to hospitalizations resulting from erythromycin non-susceptibility. Among patients under age 18 years, erythromycin non-susceptibility was estimated to cause 17\% of hospitalizations for pneumonia and \$38 million in costs, or 39\% of pneumococcal pneumonia costs attributable to resistance.

Conclusions: We estimate that antibiotic resistance in pneumococcal pneumonia leads to substantial healthcare utilization and cost, with more than one-third driven by macrolide resistance in children. With $5 \%$ of total pneumococcal costs directly attributable to resistance, strategies to reduce antibiotic resistance or improve antibiotic selection could lead to substantial savings.
\end{abstract}

Keywords: Streptococcus pneumoniae, Antibiotic resistance, Healthcare utilization, DRSP

\section{Background}

Streptococcus pneumoniae (pneumococcus) causes a variety of clinical syndromes, including acute otitis media, pneumonia, and meningitis. Although several pneumococcal vaccines have been developed (including pneumococcal polysaccharide vaccine 23 (PPSV23) in 1983, pneumococcal conjugate vaccine 7 (PCV7) in 2000, and pneumococcal conjugate vaccine 13 (PCV13) in 2010),

\footnotetext{
* Correspondence: courtner@uci.edu

'Division of Infectious Diseases and Health Policy Research Institute, University of California Irvine School of Medicine, 100 Theory Ave, Suite 110, Irvine, CA 92697, USA

Full list of author information is available at the end of the article
}

the burden of pneumococcal disease remains high across age groups, in the United States and abroad [1-10]. Our previously published model of pneumococcal burden in the United States estimated that pneumococcus was responsible for 4 million disease episodes in 2004, with acute otitis media in children accounting for the majority of cases [11]. Vaccination has led to large reductions for invasive pneumococcal diseases, yet Active Bacterial Core surveillance (ABCs) identified approximately 36,850 cases of invasive pneumococcal disease in the US in 2011 [12]. This continued high incidence of invasive 
pneumococcal disease is attributable to disease caused by non-vaccine serotypes $[13,14]$.

A major concern for treatment of pneumococcal disease is the increasing frequency of antibiotic resistance [15]. These strains are primarily resistant to penicillin, macrolides and, to a lesser extent, fluoroquinolones [16]. Among the 36,850 invasive pneumococcal disease cases identified by ABCs in 2011, 9\% were caused by penicillin non-susceptible strains and $26 \%$ were caused by erythromycin non-susceptible strains [12]. In addition, despite overall reductions in the incidence of resistant IPD, the prevalence of some multi-drug resistant strains, such as serotype 19A in the United States, increased due to serotype replacement and capsular switching following the introduction of PCV7 in 2000 [15,17,18]. The financial impact of antibiotic-resistant pneumococcus has not been evaluated and is likely to depend upon many factors including whether antibiotic treatment is concordant or discordant with the susceptibility profile of the infecting strain. Discordant treatment may result in delayed cure, multiple outpatient visits or hospitalization, and increases in morbidity, mortality and cost.

We used a previously developed decision tree-based model of U.S. pneumococcal disease burden to estimate the impact of antibiotic resistance upon healthcare utilization and cost [11]. We focused our analysis on pneumonia, as our prior study found that pneumococcal pneumonia accounted for 866,000 annual cases $(22 \%$ of pneumococcal disease burden) and $\$ 4.9$ billion dollars, or $72 \%$, of total healthcare and time-related costs attributable to pneumococcal disease.

\section{Methods}

We assessed the attributable burden of resistance using a previously published decision-tree model of pneumococcal disease burden in the United States in 2004 [11]. Model inputs and assumptions for an example pediatric $(0-<5$ yrs $)$ and adult (50- $<65$ yrs) age group are provided in Table 1. All uses of the term "resistance" denote the combination of intermediate or high level resistance. Since minimum inhibitory concentration (MIC) breakpoints for penicillin were changed in 2008, we performed most analyses using both old and new sets of breakpoints. We assumed that the effects of antibiotic resistance occurred only in the presence of discordance between the antibiotic chosen for treatment and the susceptibility of the infecting organism. From expert opinion, we estimated what fraction of patients with discordant therapy would have delayed cure, resulting in additional outpatient visits, courses of antibiotics, or hospitalization. We further assumed that inpatient antibiotic coverage was sufficiently broad that treatment failure resulting from discordant therapy only occurred in the outpatient setting. This study was exempted from human research oversight by the Harvard Pilgrim Health Care Institutional Review Board.

Table 1 Inputs and assumptions for outpatient pneumococcal pneumonia for sample pediatric and adult age groups: $0-<5$ and $50-<65$ years*

\begin{tabular}{|c|c|c|c|c|c|c|c|c|c|}
\hline \multirow[b]{3}{*}{$\begin{array}{c}\text { Sample } \\
\text { age groups }\end{array}$} & \multirow[b]{3}{*}{ Antibiotic } & \multirow[b]{3}{*}{$\begin{array}{l}\% \text { cases } \\
\text { receiving } \\
\text { antibiotic }\end{array}$} & \multirow[b]{3}{*}{$\begin{array}{c}\% \text { cases } \\
\text { treated } \\
\text { discordantly }\end{array}$} & \multicolumn{6}{|c|}{ Outcomes (\% Cases) } \\
\hline & & & & \multicolumn{3}{|c|}{ Concordant treatment } & \multicolumn{3}{|c|}{ Discordant treatment } \\
\hline & & & & $\begin{array}{l}\% \text { simple } \\
\text { cure }\end{array}$ & $\begin{array}{c}\text { \% delayed } \\
\text { cure }\end{array}$ & $\begin{array}{c}\% \text { delayed } \\
\text { cure and } \\
\text { hospitalized }\end{array}$ & $\begin{array}{l}\% \text { simple } \\
\text { cure }\end{array}$ & $\begin{array}{l}\text { \% delayed } \\
\text { cure }\end{array}$ & $\begin{array}{c}\% \text { delayed } \\
\text { cure and } \\
\text { hospitalized }\end{array}$ \\
\hline \multirow{7}{*}{$\begin{array}{l}\text { Pediatric } \\
(0-<5 \text { yrs })\end{array}$} & Amoxicillin (High dose) & $9 \%$ & $37 \%$ & $71 \%$ & $24 \%$ & $5 \%$ & $69 \%$ & $23 \%$ & $8 \%$ \\
\hline & Amoxicillin (Low dose) & $7 \%$ & $37 \%$ & $71 \%$ & $24 \%$ & $5 \%$ & $68 \%$ & $23 \%$ & $9 \%$ \\
\hline & Augmentin & $11 \%$ & $37 \%$ & $71 \%$ & $24 \%$ & $5 \%$ & $69 \%$ & $23 \%$ & $8 \%$ \\
\hline & Azithromycin & $28 \%$ & $32 \%$ & $71 \%$ & $24 \%$ & $5 \%$ & $45 \%$ & $15 \%$ & $40 \%$ \\
\hline & $\begin{array}{l}\text { Oral Cephalosporin } \\
\left(2^{\text {nd }} \text { generation }\right)\end{array}$ & $7 \%$ & $8 \%$ & $71 \%$ & $24 \%$ & $5 \%$ & $68 \%$ & $22 \%$ & $10 \%$ \\
\hline & $\begin{array}{l}\text { Oral Cephalosporin } \\
\left(3^{\text {rd }} \text { generation }\right)\end{array}$ & $24 \%$ & $8 \%$ & $71 \%$ & $24 \%$ & $5 \%$ & $68 \%$ & $22 \%$ & $10 \%$ \\
\hline & IM Ceftriaxone & $14 \%$ & $8 \%$ & $71 \%$ & $24 \%$ & $5 \%$ & $68 \%$ & $23 \%$ & $10 \%$ \\
\hline \multirow{6}{*}{$\begin{array}{c}\text { Adult } \\
(50-<65 \text { yrs })\end{array}$} & Amoxicillin & $2 \%$ & $37 \%$ & $81 \%$ & $14 \%$ & $5 \%$ & $77 \%$ & $14 \%$ & $9 \%$ \\
\hline & Augmentin & $19 \%$ & $37 \%$ & $81 \%$ & $14 \%$ & $5 \%$ & $77 \%$ & $14 \%$ & $9 \%$ \\
\hline & Azithromycin & $15 \%$ & $29 \%$ & $81 \%$ & $14 \%$ & $5 \%$ & $51 \%$ & $9 \%$ & $40 \%$ \\
\hline & $\begin{array}{l}\text { Oral Cephalosporin } \\
\text { (3rd generation) }\end{array}$ & $9 \%$ & $6 \%$ & $81 \%$ & $14 \%$ & $5 \%$ & $77 \%$ & $14 \%$ & $10 \%$ \\
\hline & IM Ceftriaxone & $5 \%$ & $6 \%$ & $81 \%$ & $14 \%$ & $5 \%$ & $77 \%$ & $14 \%$ & $10 \%$ \\
\hline & Fluoroquinolones & $56 \%$ & $1 \%$ & $81 \%$ & $14 \%$ & $5 \%$ & $51 \%$ & $9 \%$ & $40 \%$ \\
\hline
\end{tabular}

*Derived from reference 11. Two age groups are shown as examples of model assumptions and inputs. 
The incidence of outpatient pneumonia cases was obtained from the 2004-2005 National Ambulatory Medical Care Survey and 2004-2005 National Hospital Ambulatory Medical Care Survey using ICD-9 codes (all primary and secondary diagnoses) by age. We restricted outpatient cases to those visits during which an antibiotic was prescribed. Using expert panel consensus described elsewhere, we corrected for age-specific overdiagnosis among outpatient cases (16\% for pneumonia) [11]. Also using expert opinion, we estimated the frequency of relevant treatment outcomes, based upon antibiotic susceptibility profiles. The distribution of agents prescribed was obtained from the National Ambulatory Medical Care Survey. The incidence of inpatient pneumonia cases was obtained from the 2004 National Hospital Discharge Survey and the 2004 National Inpatient Sample using ICD-9 codes (primary diagnosis only) by age. For cases requiring hospital admission, we estimated the likelihood of follow-up outpatient visits, nursing home stays and death from expert opinion and literature review. We used estimates of the number of inpatient and outpatient pneumonia cases in 2004 involving pneumococcal isolates resistant to penicillin, erythromycin and fluoroquinolones by age group from Active Bacterial Core Surveillance data (inpatient) and primary literature (outpatient). In our previous analyses using this model we assumed current prevalence of antibiotic resistance [11].

Cost associated with total pneumococcal disease burden (both sensitive and resistant strains) was estimated in our previously published paper using a combination of sources including the Federal Register, and public and private payor rates. We examined four categories of cost: 1) direct costs (including medical care), 2) costs from adverse outcomes, 3) work-loss costs, and 4) cost from lost wages. We conducted several sensitivity analyses related to cost in this manuscript, including an analysis for cost per hospital day. Further details on estimations of cost are provided in Appendices C-E of that manuscript [11]. To derive an estimate of healthcare utilization and costs due to medical visits and work loss (in 2012 dollars) attributable solely to resistance to penicillin, erythromycin and fluoroquinolones, we analyzed model outputs assuming only the existence of susceptible strains and calculating the resulting differences in cost and utilization. Resistant disease was assumed to be more likely to result in delayed cure, and, if not treated with concordant

Table 2 Estimated pneumonia burden due to antibiotic-resistant Streptococcus pneumoniae isolates

\begin{tabular}{|c|c|c|c|c|c|c|}
\hline & & & Age $(y$ & & & \\
\hline & $0-<5$ & $5-<18$ & $18-<50$ & $50-<65$ & $65+$ & Total \\
\hline Inpatient cases & & & & & & \\
\hline N (\% of total) & $40,386(10 \%)$ & $16,772(4 \%)$ & $42,789(11 \%)$ & $59,508(15 \%)$ & $241,827(60 \%)$ & 401,282 \\
\hline Susceptible isolates (pre-2008 MIC) & $32,963(82 \%)$ & $14,284(85 \%)$ & $38,329(90 \%)$ & $52,804(89 \%)$ & $215,160(89 \%)$ & 353,543 \\
\hline Susceptible isolates (post-2008 MIC) & $36,799(91 \%)$ & $15,251(91 \%)$ & $40,877(96 \%)$ & $56,559(95 \%)$ & $231,704(96 \%)$ & 381,190 \\
\hline PCN resistant isolates (pre-2008 MIC)* & $14,375(36 \%)$ & $3,522(21 \%)$ & $8,130(19 \%)$ & $12,497(21 \%)$ & $58,038(24 \%)$ & 96,562 \\
\hline PCN resistant isolates (post-2008 MIC) & $4,846(12 \%)$ & $1,174(7 \%)$ & $1,711(4 \%)$ & $2,975(5 \%)$ & $12,901(5 \%)$ & 23,607 \\
\hline ERY resistant isolates & $10,821(26 \%)$ & $3,250(19 \%)$ & $7,296(17 \%)$ & $10,811(18 \%)$ & $48,754(20 \%)$ & 80,932 \\
\hline FQ resistant isolates & $404(1 \%)$ & $168(1 \%)$ & $428(1 \%)$ & $595(1 \%)$ & $2,616(1 \%)$ & 4,211 \\
\hline Multiply resistant isolates (pre-2008 MIC) & $8,562(21 \%)$ & $2,084(12 \%)$ & $4,927(12 \%)$ & $7,603(13 \%)$ & $36,375(15 \%)$ & 59,551 \\
\hline Multiply resistant isolates (post-2008 MIC) & $2,926(7 \%)$ & $716(4 \%)$ & $1,095(3 \%)$ & $1,893(3 \%)$ & $8,115(3 \%)$ & 14,745 \\
\hline Outpatient cases & & & & & & \\
\hline$N(\%$ of total) & $119,613(26 \%)$ & $88,810(19 \%)$ & $116,427(25 \%)$ & $78,154(17 \%)$ & $61,519(13 \%)$ & 464,523 \\
\hline Susceptible isolates (pre-2008 MIC) & $97,791(82 \%)$ & $72,608(82 \%)$ & $101,297(87 \%)$ & $67,216(86 \%)$ & $53,524(87 \%)$ & 392,436 \\
\hline Susceptible isolates (post-2008 MIC) & $106,974(89 \%)$ & $79,427(89 \%)$ & $112,860(97 \%)$ & $74,729(96 \%)$ & $59,630(97 \%)$ & 433,620 \\
\hline PCN resistant isolates (pre-2008 MIC) & $44,257(37 \%)$ & $32,860(37 \%)$ & $43,078(37 \%)$ & $28,917(37 \%)$ & $22,762(37 \%)$ & 171,873 \\
\hline PCN resistant isolates (post-2008 MIC) & $14,354(12 \%)$ & $10,657(12 \%)$ & $9,314(8 \%)$ & $7,034(9 \%)$ & $4,922(8 \%)$ & 46,281 \\
\hline ERY resistant isolates & $37,728(32 \%)$ & $28,012(32 \%)$ & $33,532(29 \%)$ & $22,509(29 \%)$ & $17,718(29 \%)$ & 139,499 \\
\hline FQ resistant isolates & $1,196(1 \%)$ & $888(1 \%)$ & $1,164(1 \%)$ & $782(1 \%)$ & $681(1 \%)$ & 4,711 \\
\hline Multiply resistant isolates (pre-2008 MIC) & $31,147(26 \%)$ & $23,126(26 \%)$ & $28,595(25 \%)$ & $19,195(25 \%)$ & $15,141(25 \%)$ & 117,204 \\
\hline Multiply resistant isolates (post-2008 MIC) & $10,634(9 \%)$ & $7,895(9 \%)$ & $6,615(6 \%)$ & $4,968(6 \%)$ & $3,550(6 \%)$ & 33,662 \\
\hline
\end{tabular}

*In January 2008, the Clinical and Laboratory Standards Institute revised the minimum inhibitory concentration (MIC) for non-susceptibility to penicillin. Notes: PCN = penicillin, ERY = erythromycin, FQ = fluoroquinolone. "Resistant" includes intermediate and non-susceptible isolates. Data sources: Active Bacterial Core Surveillance data (inpatient) and primary literature (outpatient). Resistance categories are not mutually exclusive, as some strains exhibited resistance to multiple antibiotics. 
antibiotics, to incur additional medical and work loss costs. For outpatient cases with delayed cure, cost attributable to resistance reflected additional outpatient visits, courses of antibiotics, or hospitalization. No changes in initial antibiotic therapy were assumed.

Finally, we performed sensitivity analyses to model the projected attributable costs resulting from increases, from present levels, in resistance to penicillin, erythromycin and fluoroquinolones. We assumed antibiotic resistant strains would replace sensitive strains, resulting in stable overall prevalence of pneumococcal disease; this assumption is partly supported by several studies in children finding that overall carriage rates of pneumococcus in the nasopharynx remained stable despite serotype replacement with resistant strains after conjugate vaccination [19-21]. We further assumed that the amount of disease and frequency of treatment failure due to resistant strains would remain similar.

\section{Results}

Overall inpatient pneumococcal pneumonia burden was estimated to be highest among those over age 65, while outpatient visits for pneumonia were most common among children less than 5 years old (Table 2). Using current MIC breakpoints, $23 \%(93,853$ of 401,282$)$ of inpatient cases and $34 \%(156,496$ of 464,523$)$ of outpatient cases exhibited resistance to at least one antibiotic. Resistance occurred most frequently to macrolides, with $20 \%$ of inpatient cases $(80,932$ of 401,282$)$ and $30 \%$ of outpatient cases $(139,499$ of 464,523) exhibiting resistance.

To provide perspective, we also calculated resistance profiles using pre-2008 MIC breakpoints and estimated

Table 3 Estimated annual healthcare utilization attributable to antibiotic resistant strains of pneumococcus for all ages*

\begin{tabular}{|c|c|c|c|}
\hline & Children (age <18) & Adults (age $\geq 18$ ) & Total (all ages) \\
\hline \multicolumn{4}{|c|}{ Attributable to PCN resistance } \\
\hline Hospitalizations** & 867 & 471 & 1,338 \\
\hline Outpatient visits & 1,478 & 780 & 2,258 \\
\hline Direct medical costs*** & $3,023,332$ & $2,864,498$ & $5,887,829$ \\
\hline Total costs & $5,358,139$ & $8,916,750$ & $14,274,155$ \\
\hline \multicolumn{4}{|l|}{ Attributable to ERY resistance } \\
\hline Hospitalizations & 9,711 & 7,889 & 17,600 \\
\hline Outpatient visits & 16,557 & 12,933 & 29,490 \\
\hline Direct medical costs & $35,443,768$ & $47,185,234$ & $82,629,002$ \\
\hline Total costs & $68,096,627$ & $143,766,210$ & $211,862,838$ \\
\hline \multicolumn{4}{|l|}{ Attributable to FQ resistance } \\
\hline Hospitalizations & 0 & 399 & 399 \\
\hline Outpatient visits & 0 & 650 & 650 \\
\hline Direct medical costs & 0 & $2,425,796$ & $2,425,796$ \\
\hline Total costs & 0 & $6,935,208$ & $6,935,208$ \\
\hline \multicolumn{4}{|c|}{ Attributable to PCN, ERY, or FQ resistance } \\
\hline Hospitalizations & 10,578 & 8,758 & 19,336 \\
\hline Outpatient visits & 18,035 & 14,363 & 32,398 \\
\hline Direct medical costs & $38,467,099$ & $52,475,527$ & $90,942,627$ \\
\hline Total costs & $73,454,767$ & $159,617,433$ & $233,072,201$ \\
\hline \multicolumn{4}{|c|}{ All cases (susceptible and resistant) } \\
\hline Hospitalizations & 57,158 & 344,124 & 401,282 \\
\hline Outpatient visits & 435,967 & 729,334 & $1,165,301$ \\
\hline Direct medical costs & $265,374,908$ & $2,295,429,821$ & $2,560,804,729$ \\
\hline Total costs & $555,738,333$ & $4,407,889,411$ & $4,963,627,745$ \\
\hline
\end{tabular}

Note: $\mathrm{PCN}=$ penicillin, ERY = erythromycin, FQ = fluoroquinolone. "Resistant" includes intermediate and non-susceptible isolates. Post-2008 MIC breakpoints were used for penicillin resistance.

${ }^{*}$ All hospitalizations due to resistance were the result of failed therapy for patients treated initially in the outpatient setting.

**Hospitalizations include admissions from the emergency department.

***All costs are expressed in 2012 dollars. Direct medical costs exclude work and productivity loss. 
that $30 \%(121,503$ of 401,282$)$ of inpatient pneumococcal cases and $42 \%(197,680$ of 464,523$)$ of outpatient cases of pneumococcal pneumonia involved resistance to one or more of the three antibiotics studied. Using pre-2008 breakpoints, resistance would have occurred most frequently to penicillin, with nearly $50 \%(59,551$ of 121,503$)$ of resistant inpatient isolates and $60 \%(117,204$ of 197,680$)$ of resistant outpatient isolates exhibiting resistance to multiple antibiotics.

Our model estimated that resistance to penicillin, erythromycin and fluoroquinolones directly caused 32,398 excess outpatient visits and 19,336 excess hospitalizations for pneumonia (Table 3). Overall, the incremental cost of antibiotic resistance was estimated to account for 4\% (\$91 million) of annual pneumococcal pneumonia direct medical costs and 5\% (\$233 million) of total costs (including work and productivity loss). Most of the incremental medical cost ( $\$ 82$ of $\$ 91$ million) was estimated to be due to hospitalizations resulting from erythromycin resistance. Among the 139,499 cases of outpatient pneumonia resistance to erythromycin, we estimated from expert opinion that 50,285 of these cases (36\%) were actually treated with erythromycin. Among these 50,285 cases given discordant treatment, $49 \%$ still resulted in simple cure, $11 \%$ resulted in delayed outpatient resolution and $40 \%$ resulted in hospitalization due to failure to improve.
While pediatric patients contributed to fewer than $15 \%$ of inpatient pneumonia cases, they constituted $45 \%$ of outpatient cases. Since costs attributable to antibiotic resistance resulted from failure of outpatient cases only, discordant treatment of pediatric cases contributed significantly to overall healthcare utilization and costs related to resistance. In particular, erythromycin resistance among patients under age 18 caused $17 \%$ of hospitalizations - that otherwise would not have occurred-and \$38 million in costs.

The projected costs of future increases in resistance (vs. baseline costs from 2004 estimates, expressed in 2012 dollars) to specific antibiotics are shown in Figure 1. This figure assumes a linear relationship between the number of resistant cases and the associated cost. Increased resistance to erythromycin was associated with the greatest projected cost.

\section{Discussion}

We estimated that more than one-third of pneumococcal pneumonia cases involved resistance to penicillin, erythromycin or fluoroquinolones. While antibiotic-resistant strains accounted for a substantial portion of inpatient and outpatient pneumococcal pneumonia cases, resistance itself was responsible for a far lower percentage of total pneumococcal pneumonia medical costs (4\%) and total

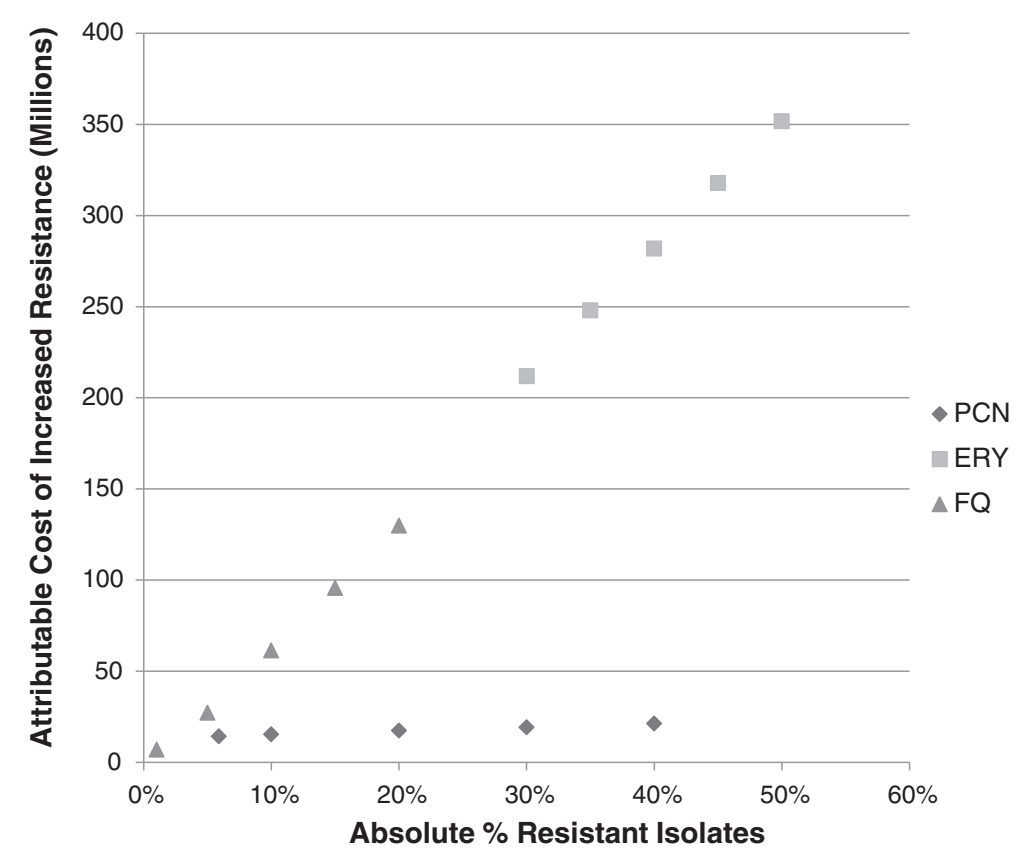

Figure 1 Projected increased costs associated with increases in resistance to specific antibiotics. Incidence of pneumococcal pneumonia is assumed to be constant. The attributable costs shown are derived from treatment failure of cases presenting as outpatients, which resulted in additional outpatient visits or courses of antibiotics, or led to hospitalizations. PCN resistance is given according to post-2008 MIC breakpoints. Cost is depicted at a given absolute percent resistance; e.g., if $20 \%$ of pneumococcal isolates were to be resistant to fluoroquinolones, the total cost attributable to that level of resistance is \$127 million dollars. Initial data points for each antibiotic indicate baseline cost and resistance. 
costs (5\%). This finding is due in part to the fact that discordant therapy and the resulting treatment failure were assumed to only occur in the outpatient setting. Because empiric therapy recommended by national guidelines address resistant infections, we assumed that inpatient treatment would cover resistant organisms for community-acquired pneumococcal pneumonia [22,23]. Nevertheless, costs attributable to resistance amount to over $\$ 90$ million in direct medical and $\$ 230$ million in total costs. Nearly all costs associated with antibiotic resistance resulted from outpatient discordant therapy that led to delays in cure, ultimately requiring additional courses of antibiotics, additional outpatient visits or hospitalization for resolution.

While resistance to penicillin was the most common, the majority of associated costs were due to erythromycin resistance. In particular, macrolide resistant pneumonia in children comprised 39\% of total associated costs due to resistance, primarily resulting from hospitalization of cases initially treated in the outpatient setting. From expert opinion, we estimated that $32 \%$ of pediatric outpatient pneumococcal pneumonia cases treated with erythromycin were discordant, resulting in an additional 9700 hospitalizations annually due to delayed resolution. To address the threat of macrolide failure, recent guidelines on community-acquired pneumonia from the Pediatric Infectious Disease Society recommend amoxicillin as first line therapy, with macrolides recommended only if there is suggestion of infection with atypical organisms [22].

Based upon our projections of increased costs due to rising levels of antibiotic resistance, increases in erythromycin resistance are most likely to result in significant increases in cost. This is in agreement with our finding that delayed cure after treatment with erythromycin, predominantly in the pediatric population, is responsible for the majority of costs currently associated with antibiotic resistant pneumococcal infections. Projected increases in resistance are simply reasonable guesses based on current levels of resistance; more dramatic increases in resistance are certainly possible, and would be associated with greater increases in cost.

This study has several limitations. We estimated the impact of antibiotic resistance using an existing decision tree model of pneumococcal disease burden from 2004. The burden of antibiotic resistant cases of pneumococcal pneumonia may have changed substantially since then. We also assumed that antibiotic resistance among nonbacteremic cases was similar to bacteremic cases. In addition, the effects of the 2010 PCV13 introduction on disease burden are not reflected in these estimates. For example, emerging antibiotic resistance in replacement non-vaccine serotypes are difficult to predict and are not addressed in this pre-PCV13 model. Our model benefits from incorporation of extensive data from administrative data sources and an expert panel; however the results are highly sensitive to assumptions about the frequency of discordant therapy for which we did not directly collect data. Our model also assumed that the costs of antibiotic resistance were exclusively due to additional treatment failure for cases initially treated in the outpatient setting; this assumption does not account for the possibility of additional delayed cure among inpatients. However, we believe that the use of broad-spectrum antibiotics for inpatient treatment renders delayed cure much less likely in this setting. In our sensitivity analyses, we assumed that rising resistance would have no effect on virulence; however it has been shown that serotypes differ in their ability to cause disease and thus we likely under-estimated the projected cost associated with increased levels of antibiotic resistant strains [24]. Lastly, we assumed that further increases in resistant strains would not result in changes in empirical prescribing practices, although this is likely if levels of resistance substantially rise.

Despite the introduction of pneumococcal vaccines, the burden of pneumococcal pneumonia remains high. While we estimated that antibiotic resistance was only associated with $4 \%$ of total pneumococcal healthcare costs, the absolute cost attributed to antibiotic resistance and treatment failure was considerable. Strategies to reduce antibiotic resistance or improve antibiotic selection may prevent a significant number of hospitalizations and outpatient visits and lead to a substantial savings.

\section{Competing interests}

The author declared that they have no competing interests.

\section{Authors' contributions}

JF, MM and SH determined the study design. GR built the mathematical model and ran all analyses using this model. CR composed the tables and figures and wrote the manuscript. All authors read and approved the final manuscript.

\section{Acknowledgements}

We are grateful to the following expert panel members for their time and expertise provided to this project: Dr. Steven Black, Dr. Ralph Gonzales, Dr. Marie Griffin, Dr. Keith Klugman, Dr. Katherine O'Brien, Dr. Lionel Mandel, and Dr. Daniel Musher. We would also like to thank Dr. Antonio Anzueto, Dr. Peter Lindenhauer, Dr. Lauri Hicks, and Sara Schoenfeld for their contributions, as well as Dr. Mark Messonnier for advice on economic methods. This study was funded by a grant from the CDC (TS-1363, Finkelstein). The findings and conclusions in this paper are those of the authors and do not necessarily represent the views of the CDC.

\section{Financial support}

This study was funded by the Centers for Disease Control and Prevention (CDC) (TS-1363, Finkelstein).

\section{Author details}

'Division of Infectious Diseases and Health Policy Research Institute, University of California Irvine School of Medicine, 100 Theory Ave, Suite 110, Irvine, CA 92697, USA. ²Department of Population Medicine, Harvard Medical School and Harvard Pilgrim Health Care Institute, 133 Brookline Ave, 3rd Floor, Boston, MA 02215, USA. ${ }^{3}$ Division of General Pediatrics, Boston Children's Hospital, 300 Longwood Ave, Hunnewell G, Boston, MA 02115, USA. ${ }^{4}$ Division of Research, Kaiser Permanente, 2000 Broadway, Oakland, CA 94612, USA. ${ }^{5}$ Centers for Disease Control and Prevention, 1600 Clifton Road, Atlanta, GA 30333, USA. 
Received: 22 October 2013 Accepted: 22 April 2014

Published: 21 May 2014

\section{References}

1. Butler JC, Breiman RF, Campbell JF, Lipman HB, Broome CV, Facklam RR: Pneumococcal polysaccharide vaccine efficacy. An evaluation of current recommendations. J Am Med Assoc 1993, 270:1826-1831.

2. Shapiro ED, Berg AT, Austrian R, Schroeder D, Parcells V, Margolis A, Adair RK, Clemens JD: The protective efficacy of polyvalent pneumococcal polysaccharide vaccine. N Engl J Med 1991, 325(21):1453-1460.

3. Centers for Disease Control and Prevention (CDC): Pneumonia hospitalizations among young children before and after introduction of pneumococcal conjugate vaccine - United States, 1997-2006. MMWR Morb Mortal Wkly Rep 2009, 8(01):1-4.

4. Lexau CA, Lynfield R, Danila R, Pilishvili T, Facklam R, Farley MM, Harrison LH, Schaffner W, Reingold A, Bennett NM, Hadler J, Cieslak PR, Whitney CG, Active Bacterial Core Surveillance Team: Changing epidemiology of invasive pneumococcal disease among older adults in the era of pediatric pneumococcal conjugate vaccine. J Am Med Assoc 2005, 294:2043-2051.

5. Whitney CG, Farley MM, Hadler J, Harrison LH, Bennett NM, Lynfield R, Reingold A, Cieslak PR, Pilishvili T, Jackson D, Facklam RR, Jorgensen JH, Schuchat A, Active Bacterial Core Surveillance of the Emerging Infections Program Network: Decline in invasive pneumococcal disease after the introduction of protein-polysaccharide conjugate vaccine. N Engl J Med 2003, 348(18):1737-1746

6. Mokaddas E, Albert MJ: Impact of pneumococcal conjugate vaccines on burden of invasive pneumococcal disease and serotype distribution of Streptococcus pneumoniae isolates: an overview from Kuwait. Vaccine 2012, 30(Suppl 6):G37-G40

7. Mueller JE, Yaro S, Ouedraogo MS, Levina N, Njanpop-Lafourcade BM, Tall H, Idohou RS, Sanou O, Kroman SS, Drabo A, Nacro B, Millogo A, van der Linden M, Gessner BD: Pneumococci in the African meningitis belt: meningitis incidence and carriage prevalence in children and adults. PLoS One 2012, 7(12):e52464.

8. Muhammed RD, Oza-Frank R, Zell E, Link-Gelles R, Narayan KM, Schaffner W, Thomas A, Lexau C, Bennett NM, Farley MM, Harrison LH, Reingold A, Hadler J, Beall B, Klugman KP, Moore MR: Epidemiology of invasive pneumococcal disease among high-risk adults since the introduction of pneumococcal conjugate vaccine for children. Clin Infect Dis 2013, 56(5):e59-e67.

9. Rosselli D, Rueda JD: Burden of pneumococcal infection in adults in Colombia. J Infect Public Health 2012, 5(5):354-359.

10. Al Musawi M: A retrospective epidemiological study of invasive pneumococcal infections in children aged 0-5 years in Bahrain from 1 January 1999 to 31 December 2003. Vaccine 2012, 30(Suppl 6):G2-G6.

11. Huang SS, Johnson KM, Ray GT, Wroe P, Lieu TA, Moore MR, Zell ER, Linder $J A$, Grijalva CG, Metlay JP, Finkelstein JA: Healthcare utilization and cost of pneumococcal disease in the United States. Vaccine 2011, 29:3398-3412.

12. Centers for Disease Control and Prevention 2013: Active Bacterial Core Surveillance Report, Emerging Infections Program Network, Streptococcus pneumoniae. 2011. http://www.cdc.gov/abcs/reportsfindings/survreports/spneu11.pdf.

13. Jackson LA, Janoff EN: Pneumococcal vaccination of elderly adults: new paradigms for protection. Clin Infect Dis 2008, 47(10):1328-1338.

14. Simonsen L, Taylor RJ, Young-Xu Y, Haber M, May L, Klugman KP: Impact of pneumococcal conjugate vaccination of infants on pneumonia and influenza hospitalization and mortality in all age groups in the United States. MBio 2011, 2(1):e00309-e00310.

15. Song JH, Dagan R, Klugman KP, Fritzell B: The relationship between pneumococcal serotypes and antibiotic resistance. Vaccine 2012, 30(17):2728-2737.

16. Hicks LA, Chien YW, Taylor TH Jr, Haber M, Klugman KP, on behalf of the Active Bacterial Core Surveillance (ABCS) Team: Outpatient antibiotic prescribing and nonsusceptible streptococcus pneumoniae in the United States, 1996-2003. Clin Infect Dis 2011, 53(7):631-639.

17. Hanage WP, Bishop CJ, Huang SS, Stevenson AE, Pelton SI, Lipsitch M, Finkelstein JA: Carried pneumococci in Massachusetts children: the contribution of clonal expansion and serotype switching. Pediatr Infect Dis J 2011, 30(4):302-308

18. Weinberger DM, Malley R, Lipsitch M: Serotype replacement in disease after pneumococcal vaccination. Lancet 2011, 378(9807):1962-1973.
19. Wroe PC, Lee GM, Finkelstein JA, Pelton SI, Hanage WP, Lipsitch M, Stevenson AE, Rifas-Shiman SL, Kleinman K, Dutta-Linn MM, Hinrichsen VL, Lakoma M, Huang SS: Pneumococcal carriage and antibiotic resistance in young children before 13-valent conjugate vaccine. Pediatr Infect Dis J 2013, 31(3):249-254.

20. Hanage WP, Bishop CJ, Lee GM, Lipsitch M, Stevenson A, Rifas-Shiman SL, Pelton SI, Huang SS, Finkelstein JA: Clonal replacement among 19A streptococcus pneumoniae in Massachusetts, prior to 13 valent conjugate vaccination. Vaccine 2011, 29(48):8877-8881.

21. Lee GM, Kleinman K, Pelton SI, Hanage W, Huang SS, Lakoma M, Dutta-Linn M, Croucher NJ, Stevenson A, Finkelstein JA: Impact of PCV13 vaccination on streptococcus pneumoniae carriage in young children in Massachusetts. J Pediatr Infect Dis Soc 2014, 3(1):23-32.

22. Bradley JS, Byington CL, Shah SS, Alverson B, Carter ER, Harrison C, Kaplan SL, Mace SE, McCracken GH Jr, Moore MR, St Peter SD, Stockwell JA, Swanson JT, Pediatric Infectious Diseases Society and the Infectious Diseases Society of America: The management of community-acquired pneumonia in infants and children older than 3 months of age: clinical practice guidelines by the pediatric infectious diseases society and the infectious diseases society of America. Clin Infect Dis 2011, 53(7):617-630.

23. Mandell LA, Wunderink RG, Anzueto A, Bartlett JG, Campbell GD, Dean NC, Dowell SF, File TM Jr, Musher DM, Niederman MS, Torres A, Whitney CG, Infectious Diseases Society of America; American Thoracic Society: Infectious diseases society of America/American thoracic society consensus guidelines on the management of community-acquired pneumonia in adults. Clin Infect Dis 2007, 44(Suppl 2):S27-S72.

24. Hanage WP, Kaijalainen TH, Syrjanen RK, Auranen K, Leinonen M, Makela PH, Spratt BG: Invasiveness of serotypes and clones of streptococcus pneumoniae among children in Finland. Infect Immun 2005, 73(1):431-435.

doi:10.1186/2047-2994-3-16

Cite this article as: Reynolds et al: Attributable healthcare utilization and cost of pneumoniae due to drug-resistant Streptococcus pneumoniae: a cost analysis. Antimicrobial Resistance and Infection Control 2014 3:16.

\section{Submit your next manuscript to BioMed Central and take full advantage of:}

- Convenient online submission

- Thorough peer review

- No space constraints or color figure charges

- Immediate publication on acceptance

- Inclusion in PubMed, CAS, Scopus and Google Scholar

- Research which is freely available for redistribution 